\title{
REVIEW
}

\section{Oscillatory fluid-induced mechanobiology in heart valves with parallels to the vasculature}

\author{
Chia-Pei Denise Hsu, Joshua D Hutcheson and Sharan Ramaswamy \\ Engineering Center, Department of Biomedical Engineering, Florida International University, Miami, Florida, USA \\ Correspondence should be addressed to S Ramaswamy: sramaswa@fiu.edu
}

\begin{abstract}
Forces generated by blood flow are known to contribute to cardiovascular development and remodeling. These hemodynamic forces induce molecular signals that are communicated from the endothelium to various cell types. The cardiovascular system consists of the heart and the vasculature, and together they deliver nutrients throughout the body. While heart valves and blood vessels experience different environmental forces and differ in morphology as well as cell types, they both can undergo pathological remodeling and become susceptible to calcification. In addition, while the plaque morphology is similar in valvular and vascular diseases, therapeutic targets available for the latter condition are not effective in the management of heart valve calcification. Therefore, research in valvular and vascular pathologies and treatments have largely remained independent. Nonetheless, understanding the similarities and differences in development, calcific/fibrous pathologies and healthy remodeling events between the valvular and vascular systems can help us better identify future treatments for both types of tissues, particularly for heart valve pathologies which have been understudied in comparison to arterial diseases.
\end{abstract}

\section{Introduction}

The cardiovascular system consists of a complex network of blood vessels that facilitates the flow of blood from the heart to the rest of the body. As the first fully functional organ system to form during embryonic development (1), blood vessels are essential to the transport of nutrients and metabolic waste products throughout life (2). Pathological tissue remodeling in arteries as well as in heart valves leaflets is a frequent cause of morbidity and mortality in humans; indeed, cardiovascular disease is still the most common cause of death in Western countries (3). However, the etiology of acquired valve diseases can be quite distinct from arterial atheroma progression. The objective of this review is to compare the similarities and differences in calcific pathological development between heart valves and blood vessels. Of particular focus is the role that oscillatory blood flow patterns play in biomechanicalinduced activation of diseased pathways in valvular vs vascular components in the systemic circulation. Unlike unidirectional or steady laminar flow, oscillatory flow consists of forward and reverse flow patterns with a range of oscillation intensities. While blood flow patterns are unsteady or time-dependent, they are cyclical and follow a distinct pulsatile pattern. This pulsatility can in turn lead to temporal blood flow oscillations when the flow direction is reversed at specific spatial locations within the cardiovascular system (e.g. fibrosa side of aortic valves). A preceding event that leads to oscillatory blood flow patterns is that of substantial blood flow deceleration 
at these specific cardiovascular sites, thereby initiating flow reversal.

\section{Aortic heart valves, aorta, and coronary arteries}

Heart valves are cardiac structures that consist of leaflets to ensure unidirectional blood flow during each cardiac cycle (4). Movements of heart valves are primarily driven by surrounding forces from the blood flow and pressure generated by cyclic contraction of heart muscles. The aorta is the largest artery that begins at the left ventricle and supplies oxygen-rich blood to the rest of the body. Coronary arteries immediately branch off from the aorta to deliver oxygen-rich blood to the entire heart. Vascular and valvular functions are regulated by both biochemical and hemodynamic factors that initiate during embryonic development and continue throughout adulthood $(5,6)$.

The aortic valve is located between the left ventricle and the aorta. They are semi-lunar valves generally composed of three separate leaflets. As the left ventricle contracts during systole, the mitral valve closes and the aortic valve opens, allowing blood flow into the aorta. During diastole, the left ventricle relaxes and the atrium contracts. The aortic valve also closes in diastole to prevent regurgitation, while the mitral valve opens to allow blood flow from the left atrium into the left ventricle. The sequence of systole and diastole repeats for each cardiac cycle in maintaining blood circulation, and the aortic valve plays a crucial role in determining the direction of blood flow. The aortic valve is the most studied valve type as it is most commonly diseased, and aortic stenosis is currently one of the most prevalent cardiovascular disease (7).

\section{Cell and extracellular matrix make-up}

The arterial wall structure is divided into three layers: tunica intima, tunica media, and tunica adventitia (Fig. 1). The layers consist primarily of elastin, collagen, and myofibroblasts, and together they form the extracellular matrix that regulates vascular elasticity. The tunica intima is primarily lined with vascular endothelial cells, which play a major role in recruitment and patterning of vascular smooth muscle cells (8). Studies have shown that smooth muscle cells are associated with formation and maintenance of vascular extracellular matrix (9).

In the systemic circulation, the aortic valve facilitates unidirectional blood flow during the systolic phase of the cardiac cycle. Each of its three leaflets consists of three layers: the ventricularis, the fibrosa, and the spongiosa (Fig. 2) (10). The ventricularis layer consists largely of

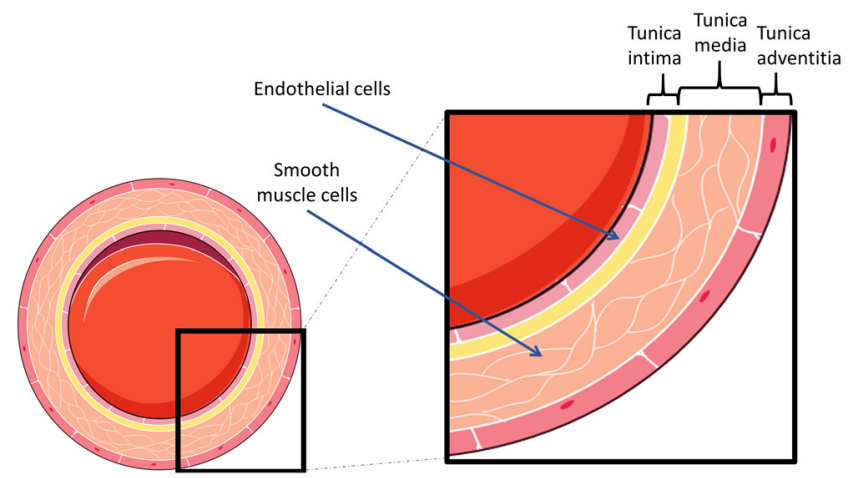

\section{Figure 1}

Structure of the arterial wall. The endothelial cells are in direct contact with blood flow in the intimal layer, while smooth muscle cells lie within the tunica media layer. Image was created from Servier Medical Art Commons (http://smart.servier.com). Servier Medical Art by Servier is licensed under a Creative Commons Attribution 3.0 Unported License.

radially aligned elastin-rich fibers facing the ventricular compartment of the heart. The fibrosa layer, located on the aortic side of the leaflet, consists of circumferentially arranged fibroblasts and collagen. The spongiosa is a layer of loose connective tissue and proteoglycans sandwiched between the ventricularis and the fibrosa layers.

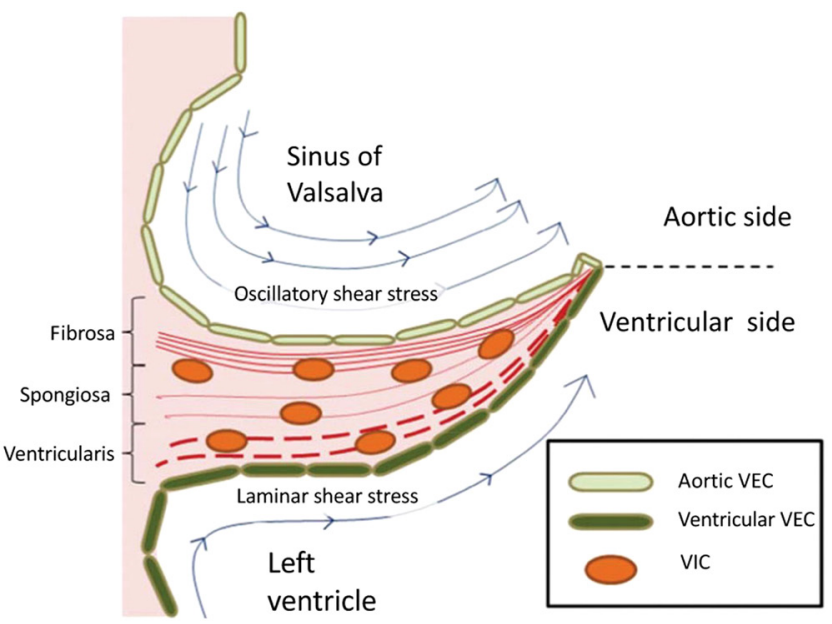

\section{Figure 2}

Aortic valve leaflet consisting of fibrosa, spongiosa, and ventricularis layers (12), which contain valve endothelial cells (VEC) on the surfaces and valve interstitial cells (VIC) deep within the tissues. The fibrosa layer is enriched with collagen, while the spongiosa layer mainly consists of glycosaminoglycans (GAGs) and the ventricularis has a high concentration of elastin fibers (11). Flow on the ventricularis side induces laminar shear stress, while the fibrosa side experiences oscillatory shear stress. The fibrosa side which is dominated by relatively lower shear stresses and disturbed, oscillatory flow patterns is a common site for calcified nodules in the manifestation of calcific aortic valve disease (CAVD). Figure reproduced with permission from Ohukainen P, Ruskoaho H \& Rysa J. Cellular Mechanisms of Valvular Thickening in Early and intermediate Calcific Aortic Valve Disease. Current Cardiology Reviews 201814 264-271. Published by Bentham Science (12). 
The outermost layer on both the fibrosa and ventricularis surfaces is covered with valve endothelial cells (VEC), which serve as a barrier to infiltration and accumulation of foreign substances. The middle layers contain valve interstitial cells (VIC), which are the most abundant cell type in heart valves and are responsible for regulating homeostasis of valve leaflet integrity (11).

\section{Calcific aortic valve disease (CAVD) and atherosclerosis}

Atherosclerosis involves narrowing of arteries due to plaque buildup. These plaques mainly consist of cholesterol, fatty substances, cellular waste products, calcium, and fibrin. They can occlude blood supply to the distal bed, and plaque rupture can activate thrombus deposition that further interrupts blood flow. Plaque deposition begins with endothelial dysfunction and unusual smooth muscle cell behavior due to environmental cues (13), in which loss of smooth muscle cell contractility leads to cell migration, plaque formation, and vascular calcification (14).

Aortic valve stenosis occurs when valve tissues become thickened or stiff, limiting blood flow from the heart to the rest of the body (Fig. 3). CAVD is a progressive disorder that ranges from mild valve thickening to severe formation of calcium phosphate nodules that impair leaflet movement (10). Formation of calcium nodules involves multiple factors, including endothelial dysfunction, inflammatory responses, as well as oxidative stresses on the valve that lead to valvular remodeling (15). Other risk factors for CAVD include hyperlipidemia, hypertension, chronic inflammation, and diabetes. Prevalence of CAVD
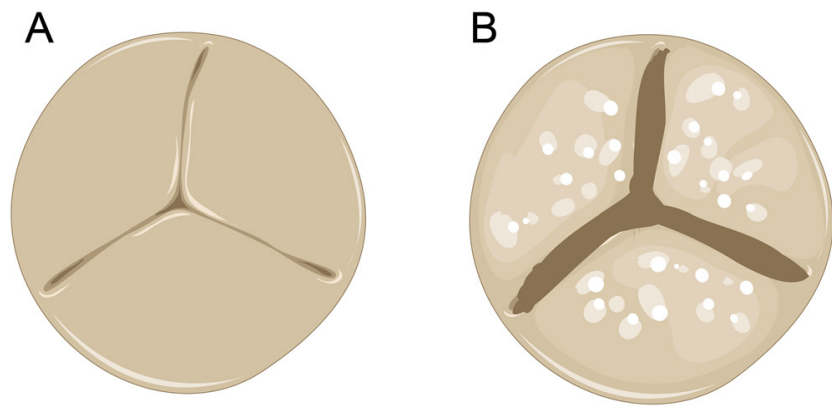

Figure 3

Closed healthy tricuspid aortic valve (A) and calcified tricuspid aortic valve (B). Calcified valves cannot open or close properly due to hardened leaflets from calcium deposition. These calcium nodules prevent the leaflet from movement or deformation. The cell types involved in pathological changes are primarily VECs and VICs; however, their specific pathological mechanisms remain unclear. Image was created from Servier Medical Art Commons (http://smart.servier.com). Servier Medical Art by Servier is licensed under a Creative Commons Attribution 3.0 Unported License. is increasing worldwide, and therapeutic methods other than surgical valve repair or replacement are not currently available. In the United States alone, CAVD is the most predominant valve disease affecting over 5.2 million people with 50,222 reported deaths in 2013 (15).

Calcified nodules prevent valve leaflets from opening or closing properly. This leads to stenosis and regurgitation, and blood delivery becomes less efficient. This phenomenon is most commonly found in aortic or mitral valve locations, even though it can occur in any of the four valves. Research has been conducted in order to better understand how calcified nodules are formed as a result of alterations in valve extracellular matrix (ECM) biochemistry, and to a lesser degree, with respect to changes in regional biomechanical conditions.

\section{Vascular vs valvular development}

\section{Vasculogenesis}

Vasculogenesis is a process involving formation of the first primitive blood vessels from the mesoderm in the early embryonic stage (16). These mesodermal cells differentiate into precursors of blood vessel endothelial cells, angioblasts, and hematopoietic cells in the lumen. Angiogenesis, on the other hand, refers to the formation of new blood vessels from preexisting ones. Previous studies have demonstrated that vasculogenesis and angiogenesis are independent processes during ontogenesis (17). During vasculogenesis, angioblasts aggregate into cords, which develop into tubular structures and blood islands. Two types of vasculogenesis processes have been identified. In type I vasculogenesis, angioblasts associate to form blood vessels in situ without migration. In type II vasculogenesis, angioblasts migrate significant distances from the original site before initial formation of the vascular plexus (18). Formation of blood vessels via type I or type II differ between species. However, both types of vasculogenesis involve endothelial cells as the building blocks of blood vessel formation (2), in addition to a family of vascular endothelial growth factors (VEGFs) in all species, which are required for angioblast differentiation, regulation of endocardial-to-mesenchymal transformation (EMT), and valve elongation $(16,19)$.

\section{Blood flow and vascular development}

Vascular development and maintenance require blood flow, as blood vessels regress in the absence of flow (20). Studies have shown that shear stresses due to blood flow are an essential environmental factor that

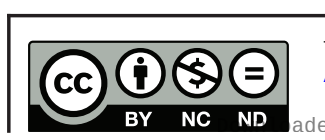

This work is licensed under a Creative Commons Attribution-NonCommercial-NoDerivatives 4.0 International License. 
activate the vascular endothelium. However, in addition to mechanotransduction properties, flow also directs secondary effects associated with chemical signaling, such as, for example, the transport of VEGF, which play a crucial role in development of vascular tissue morphology (21).

\section{Valvulogenesis}

Valve development occurs simultaneously with changes in cardiac morphology and hemodynamics. In early stages of embryonic development, the heart is a single tube which consists of endocardial cells in the myocardium (22). The endocardial cells which are similar to endothelial cells, originate from multipotent cardiovascular progenitors from the neural crest that arise from the ectoderm layer (23). The tube is surrounded by the primary myocardium which, under the presence of controlled VEGF expression, secretes a gelatin ECM known as the cardiac jelly to form cushions that later act as primitive valves. Studies have shown that an optimal physiological window of VEGF expression is essential for valve development. Within the first 4 weeks of embryonic development, a portion of endocardial cells, which originate mainly from the neural crest (24), migrate into the cardiac jelly, where they repopulate and transition into mesenchymal phenotypes (25). This process is known as the endocardial-tomesenchymal transformation (EMT) (Fig. 4). Formation of semi-lunar valves begins with expression of TBX2 and NOTCH1 to induce EMT, followed by elongation of the thick endocardial cushions into thin leaflets that exhibit a fibrous ECM structure (26).

\section{Blood flow and valve development}

Hemodynamics is one of the driving forces to valve development, and evidence has shown that blood fluidinduced stresses are essential for proper valve maturation (28). Developmentally, the outflow streams of early ventricular chambers mold the gelatin-rich cardiac jelly to shape the outflow lumen (29). The endocardial cushion subsequently becomes populated by mesenchymal cells, which thereby facilitates structured ECM for valve development (30). Investigations have shown fluid-induced, oscillatory shear stresses to be essential stimuli of valvulogenesis, via direct upregulation of the transcription factor, $k l f 2 a$ (31). Klf $2 a$ is a flow-sensitive gene necessary for the synthesis of fibronectin and heart valve formation. According to Steed et al. (32), a lack of $k l f 2 a$ expression leads to impaired cell clustering and loss of fibronectin deposition in the cardiac jelly, which are

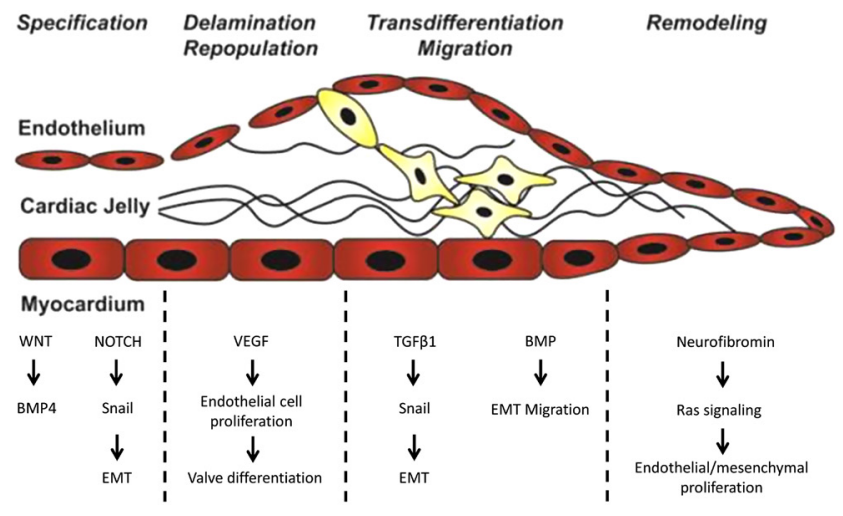

\section{Figure 4}

The cardiac jelly consists of an extracellular matrix which separates the outer myocardium layer from the inner endothelium layer. During valve formation, a small portion of the endocardial endothelial cells delaminate, differentiate, and migrate into the cardiac jelly, where they repopulate and differentiate to remodel valve tissues. Oscillatory flow-sensitive genes include WNT, NOTCH, BMP, and VEGF, which are essential components in various stages of cardiac development. Figure reproduced with permission from Armstrong EJ \& Bischoff J. Heart valve development: endothelial cell signaling and differentiation. Circulation Research 200495 459-470. Published by American heart Association (27).

critical stages of early valve development. Other studies have further shown that Bmp4 and Notch1b are additional oscillatory flow-sensitive genes critical for valve tissue formation (33).

Despite a higher lateral pressure from blood, absence of laminar flow parallel to the surface on the fibrosa side of the aortic heart valve leaflets may explain the cuboidal orientation of endothelial cells on its surface (29). On the other hand, valve patterning on the ventricularis surfaces exposed to unidirectional pulsatile flow exhibits high elastin expression, in contrast to the predominant collagen fibrils on the fibrosa surface that has considerably less exposure to unidirectional flow (34). Moreover, studies have shown that unique flow conditions in congenital valve anomalies such as in bi-cuspid aortic valves, which are prone to CAVD, regulate the valve's tissue phenotype (35). Indeed, as was previously eluded to, the formation of a bi-cuspid rather than a normal tri-leaflet aortic valve is itself associated with irregularities in developmental hemodynamics, which subsequently trigger altered cell signaling events (36).

\section{Similarities and differences}

Both vascular and valvular development begin with their respective endothelial cells, which require VEGF as a potent cytokine. In vasculature, early vascular endothelial cells derived from the mesoderm are referred to as angioblasts that aggregate to form blood islands and vascular plexus (2).

This work is licensed under a Creative Commons Attribution-NonCommercial-NoDerivatives 4.0 International License. ded from Bioscientifica.com at 04/26/2023 12:48:34AM 
In valves, on the other hand, the endocardial cells migrate into the ECM cardiac jelly and transform into mesenchymal phenotypes to form the endocardial cushion. Research has shown that endocardial cells in the heart are derived from early vascular endothelial cells during embryonic development (37). This may suggest that the endocardium and vasculature share a common progenitor and that valve leaflets are descendants of the vascular endothelium. Moreover, both endothelial cell types regulate inflammatory genes in response to abnormal hemodynamic environments, which play important roles in vascular and valvular pathogenesis (38).

\section{Vascular vs valvular disease}

\section{Vascular pathology}

Vascular diseases often initiate with damage to the endothelium. The vessel wall consists of two major cell types, endothelial cells (EC) and smooth muscle cells (SMC). ECs form monolayers that line blood vessel walls, while SMCs form multiple layers that cover the outer surface of the lumen. The ECs secrete signals required for migration and proliferation of SMCs (39). The endothelium is known to play critical roles in initiation and progression of diseases (40). During vascular injury, smooth muscle cells undergo a process of contractile-tosynthetic phenotypic switching. The synthetic vascular smooth muscle cells tend to migrate and proliferate to enhance vascular repair (41). Under normal conditions, the synthetic phenotype returns to the non-proliferative, contractile state. However, this plasticity in smooth muscle cells allows cells to respond, resulting in remodeling or, in some cases, pathology, which leads to atherosclerosis, stenosis, or hypertension (42). Environmental cues including growth factors, inflammatory mediators, and mechanical stresses may trigger phenotypic changes in vascular smooth muscle cells. Disruption of EC-SMC paracrine communication can also lead to arterial tissue destabilization and regression (39).

\section{Biomechanical context}

Blood vessels maintain integrity and function via SMC contractions and relaxations (43). Studies have found that large production of basal nitric oxide in combination with $\alpha 1$-adrenergic responses facilitates high compliance and prevents stiffening effects of SMC contractions at high pressures (44). Other studies have suggested a significant correlation between arterial stiffness and blood pressure, smoking, and circadian rhythms $(45,46,47)$.
Nonetheless, the hemodynamics have shown to influence plaque formation and regression in blood vessels, specifically the effects of absolute wall shear stresses and levels of oscillations on vascular lesions (48). The linkage between blood flow oscillations and atherosclerosis are based on two premises: the mass transport theory and the shear stress theory (49). The mass transport theory suggests that prolonged contact between blood components and the vessel wall under oscillatory flow conditions increases transport of certain substances. For instance, transport of bioactive compounds such as low-density lipoproteins may increase at sites of high oscillatory flow due to prolonged exposure of these compounds to the vessel wall. The shear stress theory, on the other hand, focuses on the effects of mechanical forces due to blood flow on vascular physiology. Some studies suggest that regions exposed to low wall shear stress magnitudes in combination with blood flow oscillations promote plaque progression (50). Other studies showed an inconclusive correlation between oscillatory wall shear stress and intimal thickening (51). The two theories are not mutually exclusive, as both influence plaque formation. Shear stresses can also alter the permeability of blood vessel walls, thereby indirectly affecting molecular mass transport (52). The combined effects of both hemodynamic parameters in the initiation of atherosclerosis remains unclear. It should be noted that hemodynamic parameters other than wall shear stress and oscillatory flow may also be involved in the onset of atherosclerosis (53).

\section{Valvular pathology}

Heart valves are subject to various ranges of mechanical stresses. In response to cyclic changes in mechanical loading, the valves undergo continuous remodeling, which can lead to pathology (54). Valve anomalies are generally associated with inflammation, osteogenesis, apoptosis, necrosis, leaflet thickening, or formation of calcium nodules (55). Early calcific lesions are characterized by increase in expression of cell adhesion molecules as well as pro-inflammatory cytokines such as transforming growth factor- $\beta 1$ (56) and bone morphogenetic proteins (57). These cytokines can then induce valve interstitial cells to switch to a fibrotic or osteoblastic phenotype $(58,59)$, which results in loss of valve tissue homeostasis, upregulation of cathepsins (60), and formation of calcific lesions.

\section{Biomechanical context}

As valve formation involves mechanically dependent processes of ECM maturation, it has been observed that

This work is licensed under a Creative Commons Attribution-NonCommercial-NoDerivatives 4.0 International License. ded from Bioscientifica.com at 04/26/2023 12:48:34AM 
valve maintenance relies heavily on mechanotransduction, which initiates from a healthy hemodynamic environment (61). Valve injury, on the other hand, can also be caused by changes in the hemodynamic environment that induces wear-and-tear of the endothelial valve tissue (62). Once endothelial injury occurs, numerous active mechanisms are triggered, such as inflammation, lipid accumulation, and changes in growth factors and cytokines, resulting in valve degeneration and calcification $(63,64)$. Studies have revealed that earliest calcium deposits form at the cusp attachments of the valve leaflets, which experience the maximum level of flexural stress. These stresses may induce tissue degeneration and ultimately calcification $(63,65)$.

The responses of the valvular endothelium are, in some respects, similar to the vascular endothelium. For example, in both cases, the transport of compounds depends on the direction of blood flow on the valve endothelial surface (66) and the alignment of VECs is dependent on the magnitude and direction of shear stress (67). However, an important distinction is the fact that aortic VECs align perpendicular to the direction of blood flow, whereas their vascular counterparts align in the parallel direction (68).

\section{Blood flow and valve disease}

Aside from mechanical stresses from bending, valve endothelial dysfunction can also result from altered bloodinduced shear stresses. Valve leaflets primarily consist of VECs and VICs, in which the VECs are mechanosensitive cells that are in direct contact with shear stresses from blood flow. VICs, on the other hand, are located within the layers of the leaflets at a higher density in the fibrosa and ventricularis than in the spongiosa (58).

\section{Similarities and differences in valve vs vascular pathology}

In both vascular and valvular systems, it has been observed that regions exposed to oscillatory shear forces are most affected by plaque development or progression of calcification (69). Physiologically relevant bloodinduced shear stresses are required for proper functioning of the endothelium. In aortic valves, fibrosa layers are consistently exposed to oscillatory shear stresses. This also correlates to a finding that the fibrosa layers have lower strain than other parts of the leaflet (70). On the other hand, in arteries, bifurcation regions experience the highest blood oscillatory forces (Fig. 5C). In both the valve and the artery, these regions of oscillations are most

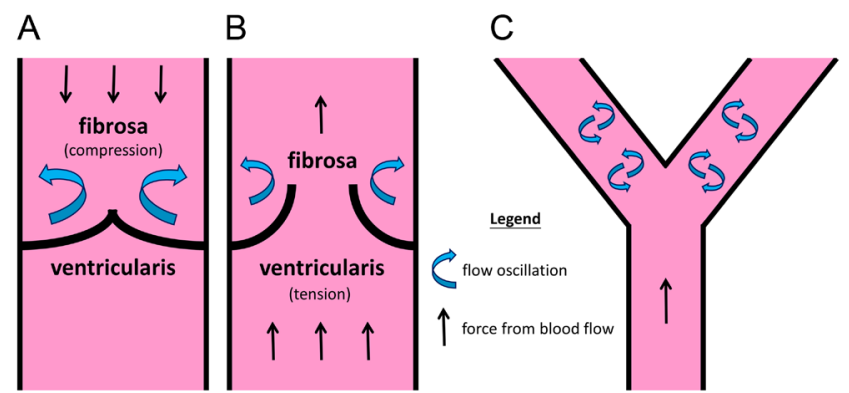

Figure 5

Regions of oscillatory blood flow in valve vs in blood vessel bifurcations. (A and B) Illustrate oscillatory flow on the leaflet's fibrosa side and the distribution of flexural compression (fibrosa) and tensile stresses (ventricularis) during valve open and closed states, respectively. (C) Depicts a straight segment of vasculature that experiences laminar flow. Oscillatory flow is formed at bifurcation sites downstream of the straight segment. It is observed that regions of flow oscillations are most vulnerable to plaque formation or calcification $(76,77)$.

prone to plaque formation $(71,72)$. Studies have shown that areas of low shear stress are prone to vascular plaque formation (73). Low shear stresses have also been found to upregulate genes associated with pro-atherosclerotic markers, wherein augmented matrix metalloproteinases (MMPs) activity has also been found $(74,75)$. Interestingly, while both oscillatory and low shear stress are needed to induce atherosclerotic plaque creation, the former induces plaque that is stable, whereas low wall shear stress is largely responsible for unstable or vulnerable plaque formation (74).

In valvular pathology, the VECs upregulate production of inflammatory cytokines that ultimately disrupt the endothelium with increased infiltration of inflammatory cells, mainly macrophages, into valve tissues (78). This infiltration can lead to changes in valve tissue mechanical properties, VIC proliferation, and calcification. Similar to valve pathology, loss of physiologically relevant shear stress in blood vessels can result in EC dysfunction, which leads to unbalanced nitric oxide production and further stimulates the formation of atherosclerotic plaques due to infiltration and proliferation of SMCs $(79,80)$. Therefore, a fundamental parallel that exists between vascular and valvular systems is the paracrine communications that occur between the endothelium and with smooth muscle cells or with valve interstitial cells, respectively. In this context, important mechanobiological triggers to pathology vs healthy tissue remodeling will depend on the magnitude of shear stresses and shear stress oscillations that are present. While a lower wall shear stress has shown to induce diseased pathways (74), it still remains unclear if the association between oscillatory force magnitudes

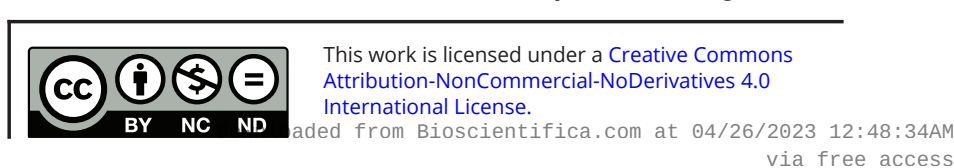


and vascular/valvular pathology is a linear relationship (e.g. higher oscillations imply more tissue degeneration) or, conversely, if there is a specific magnitude or 'sweetspot' of blood fluid-induced, oscillatory shear stresses that serve as a trigger to initiate disease (or for that matter, if there is a sweet-spot that promotes healthy vascular/ valvular tissue remodeling) (81).

A major difference between vascular and valvular pathology is the cell types involved in the progression of disease. Vascular pathology is associated with paracrine communication between EC and SMC, whereas valvular pathology involves regulation between VEC and VIC. Other differences include characterization of disease progression, in which vascular tissue forms atherosclerotic plaques, while valvular tissues form bonelike nodules. These pathological features are mainly based on differences in growth pattern, cell proliferation, and adhesion properties exhibited by vascular SMCs vs VICs (58).

\section{Vascular vs valvular remodeing}

\section{Heart valve biomechanics}

Proper heart valve function ensures unidirectional blood flow while minimizing fluid resistance and maximizing flow volume (82). The continuous opening and closing of heart valves present repetitive deformations on valve leaflets, and the leaflets remodel according to hemodynamic forces to maintain proper function. With continuous adaptation of the valve leaflet ECM in addition to the complex hemodynamic environment that activates remodeling, these tissues exhibit non-linear mechanical stress-strain relationships (83).

\section{Physiological forces and cyclic leaflet stresses}

Heart valve movements are directed by physiological blood shear stresses. Unlike the vasculature, valves experience various mechanical stresses that are caused by internalized distribution of forces from blood flow. When valve leaflet flexure occurs during the cardiac cycle, the leaflets undergo regionally varying levels of tension, compression, and fluid-induced shear stresses (Fig. 5A and B).

Studies have shown that the effective modulus E, a measure of leaflet stiffness, is significantly lower in the commissural region than the belly region (84). This allows an increase in flexural angle of the leaflet as the valves open and close. It is also observed that collagen fibers are more aligned at the commissural region compared to the belly region (85). The commissural regions also remodel at a faster rate than the belly region, suggesting that these two regions experience different time-averaged stresses (85) and, specifically, that commissural regions are subject to higher stress magnitudes (86).

\section{Pulsatile blood fluid-induced leaflet shear stresses}

Shear stress from blood flow is defined as the tangential force generated from blood flow on the endothelial surface of the valve leaflets (87). Studies have shown that, at constant heart rate, an increase in stroke volume increases shear stresses on valve leaflets. However, at constant stroke volumes, an increase in heart rate actually reduces systolic peak shear stress (88). This may be due to a shorter systolic duration at higher heart rates which, in turn, results in shorter time frame for enabling high velocities to be generated, thereby reducing peak shear stress on leaflets (88). Research has also shown fluid shear stress to be protective against valvular endothelial cell inflammation (38). Nevertheless, disturbed patterns of shear stresses were found to be pro-inflammatory (89). One of the major effects of shear stress is realignment of endothelial cells and actin fibers of the cytoskeleton (90). It is observed that valvular endothelial cells align perpendicularly in response to flow (91), while vascular endothelial cells elongate in the direction of flow (92). Studies have also shown that flow patterns are governed by valve geometry, thus flow pattern quantification may help us evaluate function and health conditions of the valve (93).

In blood vessels, normal stresses from blood pressure act perpendicularly to the vessel wall, while shear stresses from blood flow are parallel to the vessel wall surface. While normal stresses are transferred to all vessel wall layers including the intima, media, and the adventitia, shear stresses are applied to the inner endothelium in contact with blood flow (94). In heart valves, normal stresses from transvalvular pressure of $80 \mathrm{mmHg}$ is applied perpendicularly on the aortic valve leaflet surface during diastole. During systole, peak shear stresses from blood will be exerted onto the aortic leaflet surfaces on the ventricular and aortic sides, which are in the order of $64-71$ dynes $/ \mathrm{cm}^{2}$ and 20 dynes $/ \mathrm{cm}^{2}$, respectively (62). Leaflet surfaces on the aortic side also experience oscillatory shear from disturbed flow patterns, while flow on the ventricular side remains distributed in the forward flow direction. A method developed by $\mathrm{He} \&$ $\mathrm{Ku}(95)$ to quantify the extent of blood flow oscillations is known as the oscillatory shear index, which is defined as:

This work is licensed under a Creative Commons Attribution-NonCommercial-NoDerivatives 4.0 International License. ded from Bioscientifica.com at 04/26/2023 12:48:34AM 
$\mathrm{OSI}=\frac{1}{2}\left(1-\frac{\left|\int_{0}^{T} \tau_{w} d t\right|}{\int_{0}^{T}\left|\tau_{w} d t\right|}\right)$

where $\tau_{\mathrm{w}}=$ wall shear stress, $T=$ duration of cycle, and $t=$ time (95).

Shear stress serves as a principal hemodynamic stimulus in tissue remodeling. When endothelial cells are exposed to laminar physiological shear stress (15-40 dynes $/ \mathrm{cm}^{2}$ ) (96), the cells become elongated and align in one direction. In contrast, oscillatory shear stresses tend to disrupt cell alignment pattern, and the extent of these oscillations may also have an impact on the severity of endothelial dysfunction.

\section{Vascular remodeling}

Vascular remodeling is the overall adaptation of blood vessels in response to environmental stimuli. Variations in vessel wall shear stress, circumferential stress, and metabolic status can induce a response in changes in blood vessel diameter and wall thickness (97). These blood vessels react by undergoing structural changes in order to maintain their functional demands.

\section{Biomechanical context}

Studies have shown evidence that vascular remodeling is driven by variations of blood flow-induced shear stresses $(98,99)$. However, the mechanistic details of how blood vessels sense flow and respond to it in vascular remodeling is not clearly understood. Distinct markers have been found in the vascular endothelium, such as ephrinB2 and EphB4 receptors, which are specific to arterial and venous tissues, respectively (100). Analyses also suggests that differentiation of arterial or venous phenotype is mainly regulated by flow (6). For instance, vascular remodeling in zebrafish has shown transformation of arterial intersegmental vessels into venous phenotypes to create efficient blood circulation (101). This phenomenon demonstrates the plasticity of the vascular endothelium and that arterial and venous expressions may be reversible, depending on the flow environment $(102,103)$.

\section{Valvular remodeling}

Valvular remodeling is the overall adaptation of valve tissues to maintain homeostasis and undisrupted function. It involves changes in structure or form of valve components, such as the distribution of collagen and elastin within the ECM, as well as the migration or infiltration of cells. Various studies have shown that valve tissue structures undergo constant remodeling under mechanical loading (104), in which leaflet areas of stress correlate to synthesis of proteins and glycosaminoglycans (105).

\section{Biomechanical context}

Similar to vascular remodeling, valvular remodeling involves gene expression of shear-responsive factors in response to changes in blood flow. It is observed that aortic stenosis results in abnormal blood flow and an elevated load for the left ventricle. To compensate for stenotic conditions, the change in hemodynamics due to stenosis can also lead to left ventricular remodeling (106). For instance, gene expression of Tie1 in valvular endothelial cells may be essential for ECM remodeling in valve tissues (107), as Tie1 is found to be necessary for endothelial cell proliferation (108). However, due to its orphan receptor status, Tie1 is still poorly characterized (109).

\section{Blood flow and valve remodeling}

An increase in demand for blood flow has shown to affect heart development. Studies have revealed that as pregnancy increases maternal cardiac output demand due to the developing fetus, the changes in hemodynamics lead to cardiac enlargement and an increase in valve leaflet size $(110,111)$. In addition, an increase in blood volume in the developing heart has shown to change collagen architecture and leaflet composition $(112,113)$. These results indicate a strong evidence for high collagen turnover rate and complex restructuring of valvular tissue matrix due to increases in cardiovascular loading.

Statistics show that individuals with bicuspid aortic valves are more likely to acquire CAVD as compared to tri-leaflet aortic valves, due to altered blood flow patterns (114). However, the correlation between valve leaflet biomechanics and calcification remains largely unknown and remains an active area of investigation.

\section{Similarities and differences in valve vs vascular remodeling}

Vascular and valvular ECs exhibit similar morphology in static conditions, and both cell types change cell alignment and orientation in response to flow. However, alignment of vascular ECs and VECs in relation to flow direction differ in both direction and signaling pathways (92). Alignment of vascular ECs is dependent on calpain, rho-kinase, and PI3K, while VEC alignment is solely

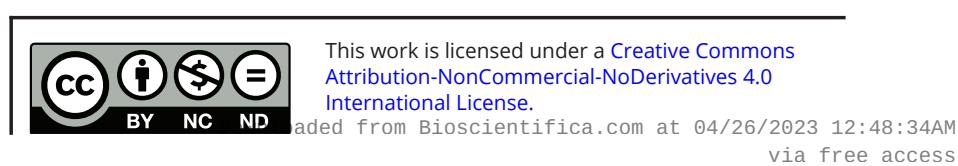


dependent on calpain and rho-kinase (92). VECs align perpendicular to fluid flow direction, whereas vascular ECs assemble in a parallel manner (92).

\section{Our laboratory's experience in valve regenerative medicine}

Currently, treatment advances for valve diseases beyond mechanical or bioprosthetic replacements is scarce. There are over 250,000 heart valve replacements every year (115). Mechanical heart valves require patients to be on life-long anticoagulant medication; bioprosthetic valves are less durable and more prone to re-calcification. Scientists and engineers have been exploring alternative treatments such as tissue engineered heart valves using bioreactor systems to deliver the proper flow, flex, and stretch conditioning $(116,117)$.

Some of the major in-house findings of tissue engineered heart valves show that when bone marrow stems cells seeded in scaffolds are exposed to a combination of flex and flow environments, the shear stresses from both flex and flow conditions generated a significantly higher amount of collagen compared flex only or flow only samples. In addition, under static (no flow) conditions, very little collagen is produced (116). This suggests that physiologically relevant flex-flow conditions promote early valvular tissue matrix development. In addition to flex-flow conditions, our laboratory has also investigated the effects of pulsatile shear stress in comparison to nonpulsatile shear on tissue cell alignment. It is observed that bone marrow stem cells respond to pulsatile shear stress with an increased level of actin filaments and a decrease in filament length, suggesting transition from a mesenchymal to endothelial phenotype, which is a crucial process in the formation of the endothelium in tissue engineered heart valves (118).

It is important to make the distinction between pulsatile flow and oscillatory flow. Fluid pulsatility may not necessarily yield oscillatory flow patterns downstream. Moreover, the specific nature of oscillatory flow patterns may elicit either a healthy or pathological cellular/tissue remodeling response. With our laboratory's (http://cvpeutics.fiu.edu/) emphasis in cardiovascular regenerative medicine applications, we have previously shown that specific oscillatory flow conditions (intermediate OSIs in the range of 0.18-0.23) promote the valvular phenotype in differentiating human bone marrow mesenchymal stem cells, as evidenced via gene expression results (81). Part of our on-going efforts are to assess if oscillatory flow conditions can additionally enhance the stem cell secretome, such as, for example, via exosome production for delivery of molecular factors, that could potentially enhance cardiovascular repair and regenerative processes.

\section{Concluding remarks and future outlook}

Heart valves and blood vessels are dynamic biological structures that play important roles in efficient blood delivery. Dysfunction and dysregulation of cellular functions lead to vascular and valvular diseases (58, 119), particularly atherosclerosis and valve stenosis (120). Early works focused on understanding cellular and ECM responses to various mechanical environments of valvular and vascular systems. The mechanisms involved in physiological or pathological conditions due to environmental adaptation remains unclear. While remodeling may repair the original vascular or valvular tissues, due to cell plasticity, they also pose a risk of developing pathology. Inflammatory cells are also known to play active roles in both ECM remodeling and calcification (121). However, determination of the pathways that lead to mineralization or remodeling require further assessment. While tissue deformation is an important factor involved in vascular and valvular repair or disease (122), variables such as the presence of cyclical flexural stresses, pulsatile blood-induced stresses, cyclical tensile stresses, inflammatory cytokines, and macrophages present major challenges in recapitulating vascular and valvular pathology in vitro. Future work will involve detailed designs of bioreactors that better simulate the mechanical and biochemical environment of native vascular and valvular tissues, with the goal of developing pharmacological therapies. Additionally, the emerging studies on the role of neuronal cell regulation and specific ECM structures in tissue remodeling (123, $124,125)$ should also be considered in these in vitro vascular/valvular tissue model systems.

\section{Declaration of interest}

The authors declare that there is no conflict of interest that could be perceived as prejudicing the impartiality of this review.

\section{Funding}

This work did not receive any specific grant from any funding agency in the public, commercial, or not-for-profit sector. (c) 2020 The authors Published by Bioscientifica Ltd
This work is licensed under a Creative Commons Attribution-NonCommercial-NoDerivatives 4.0 International License. ded from Bioscientifica.com at $04 / 26 / 2023$ 12:48:34AM 


\section{References}

1 Dweck MR, Khaw HJ, Sng GK, Luo EL, Baird A, Williams MC, Makiello P, Mirsadraee S, Joshi NV, van Beek EJ, et al. Aortic stenosis, atherosclerosis, and skeletal bone: is there a common link with calcification and inflammation? European Heart Journal $2013 \mathbf{3 4}$ 1567-1574. (https://doi.org/10.1093/eurheartj/eht034)

2 Udan RS, Culver JC \& Dickinson ME. Understanding vascular development. Wiley Interdisciplinary Reviews: Developmental Biology 20132 327-346. (https://doi.org/10.1002/wdev.91)

3 Dalen JE, Alpert JS, Goldberg RJ \& Weinstein RS. The epidemic of the 20th century: coronary heart disease. American Journal of Medicine 2014127 807-812. (https://doi.org/10.1016/j.amjmed.2014.04.015)

4 Sacks MS \& Yoganathan AP. Heart valve function: a biomechanical perspective. Philosophical Transactions of the Royal Society of London: Series B, Biological Sciences 2007362 1369-1391. (https://doi. org/10.1098/rstb.2007.2122)

5 Chester A, El-Hamamsy I, Butcher J, Latif N, Bertazzo S \& Yacoub M. The living aortic valve: from molecules to function. Global Cardiology Science and Practice 201411 1-26.

6 le Noble F, Moyon D, Pardanaud L, Yuan L, Djonov V, Matthijsen R, Bréant C, Fleury V \& Eichmann A. Flow regulates arterial-venous differentiation in the chick embryo yolk sac. Development 2004131 361-375. (https://doi.org/10.1242/dev.00929)

7 Maganti K, Rigolin VH, Sarano ME \& Bonow RO. Valvular heart disease: diagnosis and management. Mayo Clinic Proceedings 201085 483-500. (https://doi.org/10.4065/mcp.2009.0706)

8 Hellstrom M, Kalén M, Lindahl P, Abramsson A \& Betsholtz C. Role of PDGF-B and PDGFR-beta in recruitment of vascular smooth muscle cells and pericytes during embryonic blood vessel formation in the mouse. Development 1999126 3047-3055.

9 Dingemans KP, Teeling P, Lagendijk JH \& Becker AE. Extracellular matrix of the human aortic media: an ultrastructural histochemical and immunohistochemical study of the adult aortic media. Anatomical Record 2000258 1-14. (https://doi.org/10.1002/ (SICI) 1097-0185(20000101)258:1<1::AID-AR1>3.0.CO;2-7)

10 Freeman RV \& Otto CM. Spectrum of calcific aortic valve disease: pathogenesis, disease progression, and treatment strategies. Circulation 2005111 3316-3326. (https://doi.org/10.1161/ CIRCULATIONAHA.104.486738)

11 Lerman DA, Prasad S \& Alotti N. Calcific aortic valve disease: molecular mechanisms and therapeutic approaches. European Cardiology 201510 108-112. (https://doi.org/10.15420/ ecr.2015.10.2.108)

12 Ohukainen P, Ruskoaho H \& Rysa J. Cellular mechanisms of valvular thickening in early and intermediate calcific aortic valve disease. Current Cardiology Reviews 201814 264-271. (https://doi.org/10.2174 /1573403X14666180820151325)

13 Groenendyk JW \& Mehta NN. Applying the ordinal model of atherosclerosis to imaging science: a brief review. Open Heart 20185 e000861. (https://doi.org/10.1136/openhrt-2018-000861)

14 Steucke KE, Tracy PV, Hald ES, Hall JL \& Alford PW. Vascular smooth muscle cell functional contractility depends on extracellular mechanical properties. Journal of Biomechanics 201548 3044-3051. (https://doi.org/10.1016/j.jbiomech.2015.07.029)

15 Dutta P \& Lincoln J. Calcific aortic valve disease: a developmental biology perspective. Current Cardiology Reports 201820 21. (https:// doi.org/10.1007/s11886-018-0968-9)

16 Patan S. Vasculogenesis and angiogenesis as mechanisms of vascular network formation, growth and remodeling. Journal of Neuro-Oncology $2000 \mathbf{5 0}$ 1-15. (https://doi. org/10.1023/a:1006493130855)

17 Pardanaud L, Yassine F \& Dieterlen-Lievre F. Relationship between vasculogenesis, angiogenesis and haemopoiesis during avian ontogeny. Development 1989105 473-485.
18 Poole TJ \& Coffin JD. Vasculogenesis and angiogenesis: two distinct morphogenetic mechanisms establish embryonic vascular pattern. Journal of Experimental Zoology 1989251 224-231. (https://doi. org/10.1002/jez.1402510210)

19 Stankunas K, Ma GK, Kuhnert FJ, Kuo CJ \& Chang CP. VEGF signaling has distinct spatiotemporal roles during heart valve development. Developmental Biology 2010347 325-336. (https://doi. org/10.1016/j.ydbio.2010.08.030)

20 Meeson AP, Argilla M, Ko K, Witte L \& Lang RA. VEGF deprivationinduced apoptosis is a component of programmed capillary regression. Development 1999126 1407-1415.

21 Ghaffari S, Leask RL \& Jones EAV. Blood flow can signal during angiogenesis not only through mechanotransduction, but also by affecting growth factor distribution. Angiogenesis 201720 373-384. (https://doi.org/10.1007/s10456-017-9553-x)

22 Butcher JT \& Markwald RR. Valvulogenesis: the moving target. Philosophical Transactions of the Royal Society of London: Series B, Biological Sciences 2007362 1489-1503. (https://doi.org/10.1098/ rstb.2007.2130)

23 Misfeldt AM, Boyle SC, Tompkins KL, Bautch VL, Labosky PA \& Baldwin HS. Endocardial cells are a distinct endothelial lineage derived from Flk1+ multipotent cardiovascular progenitors. Developmental Biology 2009333 78-89. (https://doi.org/10.1016/j. ydbio.2009.06.033)

24 Srivastava D. Making or breaking the heart: from lineage determination to morphogenesis. Cell 2006126 1037-1048. (https:// doi.org/10.1016/j.cell.2006.09.003)

25 Monaghan MG, Linneweh M, Liebscher S, Handel B, Layland SL \& Schenke-Layland K. Endocardial-to-mesenchymal transformation and mesenchymal cell colonization at the onset of human cardiac valve development. Development 2016143 473-482. (https://doi. org/10.1242/dev.133843)

26 Lindsey SE \& Butcher JT. The cycle of form and function in cardiac valvulogenesis.. Aswan Heart Centre Science and Practice Series 2011 2011 1-17. (https://doi.org/10.5339/ahcsps.2011.10)

27 Armstrong EJ \& Bischoff J. Heart valve development: endothelial cell signaling and differentiation. Circulation Research 200495 459-470. (https://doi.org/10.1161/01.RES.0000141146.95728.da)

28 Hove JR, Koster RW, Forouhar AS, Acevedo-Bolton G, Fraser SE \& Gharib M. Intracardiac fluid forces are an essential epigenetic factor for embryonic cardiogenesis. Nature 2003421 172-177. (https://doi. org/10.1038/nature01282)

29 Maron BJ \& Hutchins GM. The development of the semilunar valves in the human heart. American Journal of Pathology 197474 331-344.

30 MacGrogan D, Luxan G, Driessen-Mol A, Bouten C, Baaijens F \& Pompa J. How to make a heart valve: from embryonic development to bioengineering of living valve substitutes. Cold Spring Harbor Perspectives in Medicine 2014 1-24.

31 Heckel E, Boselli F, Roth S, Krudewig A, Belting HG, Charvin G $\&$ Vermot J. Oscillatory flow modulates mechanosensitive klf2a expression through trpv4 and trpp2 during heart valve development. Current Biology 201525 1354-1361. (https://doi.org/10.1016/j. cub.2015.03.038)

32 Steed E, Faggianelli N, Roth S, Ramspacher C, Concordet JP \& Vermot J. klf2a couples mechanotransduction and zebrafish valve morphogenesis through fibronectin synthesis. Nature Communications 20167 11646. (https://doi.org/10.1038/ ncomms11646)

33 Vermot J, Forouhar AS, Liebling M, Wu D, Plummer D, Gharib M $\&$ Fraser SE. Reversing blood flows act through klf2a to ensure normal valvulogenesis in the developing heart. PLoS Biology 20097 e1000246. (https://doi.org/10.1371/journal.pbio.1000246)

34 Combs MD \& Yutzey KE. Heart valve development: regulatory networks in development and disease. Circulation Research 2009105 408-421. (https://doi.org/10.1161/ CIRCRESAHA.109.201566) 
35 Maleki S, Bjorck HM, Folkersen L, Nilsson R, Renner J, Caidahl K, Franco-Cereceda A, Lanne T \& Eriksson P. Identification of a novel flow-mediated gene expression signature in patients with bicuspid aortic valve. Journal of Molecular Medicine 201391 129-139. (https:// doi.org/10.1007/s00109-012-0942-8)

36 Goddard LM, Duchemin AL, Ramalingan H, Wu B, Chen M, Bamezai S, Yang J, Li L, Morley MP, Wang T, et al. Hemodynamic forces sculpt developing heart valves through a KLF2-WNT9B paracrine signaling axis. Developmental Cell 201743 274-289.e5. (https://doi.org/10.1016/j.devcel.2017.09.023)

37 Milgrom-Hoffman M, Harrelson Z, Ferrara N, Zelzer E, Evans SM $\&$ Tzahor E. The heart endocardium is derived from vascular endothelial progenitors. Development 2011138 4777-4787. (https:// doi.org/10.1242/dev.061192)

38 Butcher JT, Tressel S, Johnson T, Turner D, Sorescu G, Jo H \& Nerem RM. Transcriptional profiles of valvular and vascular endothelial cells reveal phenotypic differences: influence of shear stress. Arteriosclerosis, Thrombosis, and Vascular Biology 200626 69-77. (https://doi.org/10.1161/01.ATV.0000196624.70507.0d)

39 Gupta A \& Bhatnagar S. Vasoregression: a shared vascular pathology underlying macrovascular and microvascular pathologies? Journal of Integrative Biology 201519 733-753.

40 Rajendran P, Rengarajan T, Thangavel J, Nishigaki Y, Sakthisekaran D, Sethi G \& Nishigaki I. The vascular endothelium and human diseases. International Journal of Biological Sciences 20139 1057-1069. (https://doi.org/10.7150/ijbs.7502)

41 Finsterwalder R, Ganesan MK, Leb H, Habertheuer A, Basillo J, Lang I, krunic M, Wiedemann D \& Petzelbauer P. Hypoxia/reperfusion predisposes to atherosclerosis. PLOS ONE 201813 e0205067. (https:// doi.org/10.1371/journal.pone.0205067)

42 Owens GK, Kumar MS \& Wamhoff BR. Molecular regulation of vascular smooth muscle cell differentiation in development and disease.. Physiological Reviews 200484 767-801. (https://doi. org/10.1152/physrev.00041.2003)

43 Fransen P, Van Hove CE, Leloup AJ, Martinet W, De Meyer GR, Lemmens K, Bult H \& Schrijvers DM. Dissecting out the complex $\mathrm{Ca} 2+-$ mediated phenylephrine-induced contractions of mouse aortic segments. PLoS ONE 201510 e0121634. (https://doi. org/10.1371/journal.pone.0121634)

44 Leloup AJA, Van Hove CE, Moundt S, De Meyer GRY, De Keulenaer GW \& Fransen P. Vascular smooth muscle cell contraction and relaxation in the isolated aorta: a critical regulator of large artery compliance. Physiological Reports 20197 e13934. (https://doi. org/10.14814/phy2.13934)

45 Liu Q, Yan BP, Yu CM, Zhang YT \& Poon CC. Attenuation of systolic blood pressure and pulse transit time hysteresis during exercise and recovery in cardiovascular patients. IEEE Transactions on BioMedical Engineering 201461 346-352. (https://doi.org/10.1109/ TBME.2013.2286998)

46 Stefanadis C, Vlachopoulos C, Tsiamis E, Diamantopoulos L, Toutouzas K, Giatrakos N, Vaina S, Tsekoura D \& Toutouzas P. Unfavorable effects of passive smoking on aortic function in men. Annals of Internal Medicine 1998128 426-434. (https://doi. org/10.7326/0003-4819-128-6-199803150-00002)

47 Bia D, Armentano R, Pessana F, Zocalo Y, Lluberas S \& Avolio A. Non-symmetrical double-logistic analysis of 24 hour arterial stiffness profile in normotensive and hypertensive subjects. IEEE Engineering in Medicine and Biology Society 20082008 809-812 2008.

48 Timmins LH, Molony DS, Eshtehardi P, McDaniel MC, Oshinski JN, Giddens DP \& Samady H. Oscillatory wall shear stress is a dominant flow characteristic affecting lesion progression patterns and plaque vulnerability in patients with coronary artery disease. Journal of the Royal Society, Interface 201714 20160972. (https://doi.org/10.1098/ rsif.2016.0972)

49 Kwak BR, Back M, Bochaton-Piallat ML, Caligiuri G, Daemen MJ, Davies PF, Hoefer IE, Holvoet P, Jo H, Krams R, et al. Biomechanical factors in atherosclerosis: mechanisms and clinical implications. European Heart Journal 201435 3013-3020, 3020a-3020d. (https:// doi.org/10.1093/eurheartj/ehu353)

50 Nam D, Hi C, Rezvan A, Sui J, Budzyn K, Llanos A, Harrison D, Giddens D \& Jo H. Partial carotid ligation is a model of acutely induced disturbed flow, leading to rapid endothelial dysfunction and atherosclerosis. American Journal of Physiology: Heart and Circulatory Physiology 2009297 1535-1543.

51 Joshi AK, Leask RL, Myers JG, Ojha M, Butany J \& Ethier CR. Intimal thickness is not associated with wall shear stress patterns in the human right coronary artery. Arteriosclerosis, Thrombosis, and Vascular Biology 200424 2408-2413. (https://doi.org/10.1161/01. ATV.0000147118.97474.4b)

52 Jo H, Dull RO, Hollis TM \& Tarbell JM. Endothelial albumin permeability is shear dependent, time dependent, and reversible. American Journal of Physiology 1991260 H1992-H1996. (https://doi. org/10.1152/ajpheart.1991.260.6.H1992)

53 Amaya R, Cancel LM \& Tarbell JM. Interaction between the stress phase angle (SPA) and the oscillatory shear index (OSI) affects endothelial cell gene expression. PLoS ONE 201611 e0166569. (https://doi.org/10.1371/journal.pone.0166569)

54 Izquierdo-Gomez MM, Hernandez-Betancor I, Garcia-Niebla J, MariLopez B, Laynez-Cerdena I \& Lacalzada-Almeida J. Valve calcification in aortic stenosis: etiology and diagnostic imaging techniques. BioMed Research International 20172017 5178631. (https://doi. org/10.1155/2017/5178631)

55 Sun L, Chandra S \& Sucosky P. Ex vivo evidence for the contribution of hemodynamic shear stress abnormalities to the early pathogenesis of calcific bicuspid aortic valve disease. PLOS ONE 20127 e48843. (https://doi.org/10.1371/journal.pone.0048843)

56 Jian B, Narula N, Li QY, Mohler ER \& Levy RJ. Progression of aortic valve stenosis: TGF-beta1 is present in calcified aortic valve cusps and promotes aortic valve interstitial cell calcification via apoptosis. Annals of Thoracic Surgery 200375 457-465; discussion 465. (https:// doi.org/10.1016/s0003-4975(02)04312-6)

57 Kaden JJ, Bickelhaupt S, Grobholz R, Vahl CF, Hagl S, Brueckmann M, Haase KK, Dempfle CE \& Borggrefe M. Expression of bone sialoprotein and bone morphogenetic protein-2 in calcific aortic stenosis. Journal of Heart Valve Disease 200413 560-566.

$58 \mathrm{Liu}$ AC, Joag VR \& Gotlieb AI. The emerging role of valve interstitial cell phenotypes in regulating heart valve pathobiology. American Journal of Pathology 2007171 1407-1418. (https://doi.org/10.2353/ ajpath.2007.070251)

59 Monzack EL \& Masters KS. Can valvular interstitial cells become true osteoblasts? A side-by-side comparison. Journal of Heart Valve Disease 201120 449-463.

60 Platt MO \& Shockey WA. Endothelial cells and cathepsins: biochemical and biomechanical regulation. Biochimie 2016122 314-323. (https://doi.org/10.1016/j.biochi.2015.10.010)

61 Neri T, Hiriart E, Vliet PP, Faure E, Norris RA, Farhat B, Jagla B, Lefrancois J, Sugi Y, Moore-Morris T, et al. Human pre-valvular endocardial cells derived from pluripotent stem cells recapitulate cardiac pathophysiological valvulogenesis. Nature Communications 201910 1929. (https://doi.org/10.1038/s41467-019-09459-5)

62 Balachandran K, Sucosky P \& Yoganathan AP. Hemodynamics and mechanobiology of aortic valve inflammation and calcification. International Journal of Inflammation 20112011263870 . (https://doi. org/10.4061/2011/263870)

63 Mohler III ER. Mechanisms of aortic valve calcification. American Journal of Cardiology 200494 1396-1402, A6. (https://doi. org/10.1016/j.amjcard.2004.08.013)

64 Veinot JP. Pathology of inflammatory native valvular heart disease. Cardiovascular Pathology 200615 243-251. (https://doi. org/10.1016/j.carpath.2006.04.007)

65 Thubrikar MJ, Aouad J \& Nolan SP. Patterns of calcific deposits in operatively excised stenotic or purely regurgitant aortic valves and 
their relation to mechanical stress. American Journal of Cardiology 198658 304-308. (https://doi.org/10.1016/0002-9149(86)90067-6)

66 Zeng Z, Yin Y, Jan KM \& Rumschitzki DS. Macromolecular transport in heart valves. II. Theoretical models. American Journal of Physiology: Heart and Circulatory Physiology 2007292 H2671-H2686. (https://doi. org/10.1152/ajpheart.00608.2006)

67 Mahler GJ, Frendl CM, Cao Q \& Butcher JT. Effects of shear stress pattern and magnitude on mesenchymal transformation and invasion of aortic valve endothelial cells. Biotechnology and Bioengineering 2014111 2326-2337. (https://doi.org/10.1002/ bit.25291)

68 Davies PF, Passerini AG \& Simmons CA. Aortic valve turning over a new leaf(let) in endothelial phenotypic heterogeneity. Arteriosclerosis, Thrombosis, and Vascular Biology 200424 1331-1333. (https://doi. org/10.1161/01.ATV.0000130659.89433.c1)

69 Gomel MA, Lee R \& Grande-Allen KJ. Comparing the role of mechanical forces in vascular and valvular calcification progression. Frontiers in Cardiovascular Medicine 20185 197. (https://doi. org/10.3389/fcvm.2018.00197)

70 Vesely I \& Noseworthy R. Micromechanics of the fibrosa and the ventricularis in aortic valve leaflets. Journal of Biomechanics $1992 \mathbf{2 5}$ 101-113. (https://doi.org/10.1016/0021-9290(92)90249-z)

71 Simmons CA, Grant GR, Manduchi E \& Davies PF. Spatial heterogeneity of endothelial phenotypes correlates with sidespecific vulnerability to calcification in normal porcine aortic valves. Circulation Research 200596 792-799. (https://doi.org/10.1161/01. RES.0000161998.92009.64)

$72 \mathrm{Ku}$ DN. Blood flow in arteries. Annual Review of Fluid Mechanics 1997 29 399-434. (https://doi.org/10.1146/annurev.fluid.29.1.399)

73 Go YM, Boo YC, Park H, Maland MC, Patel R, Pritchard Jr KA, Fujio Y, Walsh K, Darley-Usmar V \& Jo H. Protein kinase B/Akt activates c-Jun NH2-terminal kinase by increasing NO production in response to shear stress. Journal of Applied Physiology 200191 1574-1581. (https://doi.org/10.1152/jappl.2001.91.4.1574)

74 Cheng C, Tempel D, Haperen R, Van der Baan A, Grosveld F, Daemen MJ, Krams R \& De Crom R. Atherosclerotic lesion size and vulnerability are determined by patterns of fluid shear stress. Circulation 2006113 2744-2753. (https://doi.org/10.1161/ CIRCULATIONAHA.105.590018)

75 Galis ZS, Sukhova GK, Lark MW \& Libby P. Increased expression of matrix metalloproteinases and matrix degrading activity in vulnerable regions of human atherosclerotic plaques. Journal of Clinical Investigation 199494 2493-2503. (https://doi.org/10.1172/JCI117619)

76 Wasilewski J, Mirota K, Wilczek K, Glowacki J \& Polonski L. Calcific aortic valve damage as a risk factor for cardiovascular events. Polish Journal of Radiology 201277 30-34. (https://doi.org/10.12659/ pjr.883626)

77 Ge L \& Sotiropoulos F. Direction and magnitude of blood flow shear stresses on the leaflets of aortic valves: is there a link with valve calcification? Journal of Biomechanical Engineering 2010132014505. (https://doi.org/10.1115/1.4000162)

78 Towler DA. Molecular and cellular aspects of calcific aortic valve disease. Circulation Research 2013113 198-208. (https://doi. org/10.1161/CIRCRESAHA.113.300155)

79 Malek AM, Alper SL \& Izumo S. Hemodynamic shear stress and its role in atherosclerosis. JAMA 1999282 2035-2042. (https://doi. org/10.1001/jama.282.21.2035)

80 Chatzizisis YS, Coskun AU, Jonas M, Edelman ER, Feldman CL \& Stone PH. Role of endothelial shear stress in the natural history of coronary atherosclerosis and vascular remodeling: molecular, cellular, and vascular behavior. Journal of the American College of Cardiology 200749 2379-2393. (https://doi.org/10.1016/j.jacc.2007.02.059)

81 Williams A, Nasim S, Salinas M, Moshkforoush A, Tsoukias N \& Ramaswamy S. A 'sweet-spot' for fluid-induced oscillations in the conditioning of stem cell-based engineered heart valve tissues.
Journal of Biomechanics 201765 40-48. (https://doi.org/10.1016/j. jbiomech.2017.09.035)

82 Sacks MS, David Merryman W \& Schmidt DE. On the biomechanics of heart valve function. Journal of Biomechanics 200942 1804-1824. (https://doi.org/10.1016/j.jbiomech.2009.05.015)

83 Weinberg EJ \& Kaazempur-Mofrad MR. On the constitutive models of heart valve leaflet mechanics. Cardiovascular Engineering 20055 37-43. (https://doi.org/10.1007/s10558-005-3072-x)

84 Mirnajafi A, Raymer JM, McClure LR \& Sacks MS. The flexural rigidity of the aortic valve leaflet in the commisural region. Journal of Biomechanics 200639 2966-2973. (https://doi.org/10.1016/j. jbiomech.2005.10.026)

85 Sacks MS, Smith DB \& Hiester ED. The aortic valve microstructure: effects of transvalvular pressure. Journal of Biomedical Materials Research 199841 131-141. (https://doi.org/10.1002/(sici)10974636(199807)41:1<131::aid-jbm16>3.0.co;2-q)

86 Sun W, Abad A \& Sacks MS. Simulated bioprosthetic heart valve deformation under quasi-static loading. Journal of Biomechanical Engineering 2005127 905-914. (https://doi.org/10.1115/1.2049337)

87 Paszkowiak JJ \& Dardik A. Arterial wall shear stress: observation from the bench to the bedside. Vascular and Endovascular Surgery 200337 47-57. (https://doi.org/10.1177/153857440303700107)

88 Yap CH, Saikrishnan N, Tamilselvan G \& Yoganathan AP. Experimental measurement of dynamic fluid shear stress on the aortic surface of the aortic valve leaflet. Biomechanics and Modeling in Mechanobiology 201211 171-182. (https://doi.org/10.1007/s10237011-0301-7)

89 Sucosky P, Balachandran K, Elhammali A, Jo H \& Yoganathan AP. Altered shear stress stimulates upregulation of endothelial VCAM-1 and ICAM-1 in a BMP-4 and TGF-beta1-dependent pathway. Arteriosclerosis, Thrombosis, and Vascular Biology 200929 254-260. (https://doi.org/10.1161/ATVBAHA.108.176347)

90 Wong AJ, Pollard TD \& Herman IM. Actin filament stress fibers in vascular endothelial cells in vivo. Science 1983219 867-869. (https:// doi.org/10.1126/science.6681677)

91 Ives CL, Eskin SG \& McIntire LV. Mechanical effects on endothelial cell morphology: in vitro assessment. In Vitro Cellular and Developmental Biology 198622 500-507. (https://doi.org/10.1007/ bf02621134)

92 Butcher JT, Penrod AM, Garcia AJ \& Nerem RM. Unique morphology and focal adhesion development of valvular endothelial cells in static and fluid flow environments. Arteriosclerosis, Thrombosis, and Vascular Biology 200424 1429-1434. (https://doi.org/10.1161/01. ATV.0000130462.50769.5a)

93 Sung HW \& Yoganathan AP. Axial flow velocity patterns in a normal human pulmonary artery model: pulsatile in vitro studies. Journal of Biomechanics 199023 201-214. (https://doi.org/10.1016/00219290(90)90012-r)

94 Papaioannou TG \& Stefanadis C. Vascular wall shear stress: basic principles and methods. Hellenic Journal of Cardiology 2005 46 9-15.

95 He X \& Ku DN. Pulsatile flow in the human left coronary artery Bifucation: average conditions. Journal of Biomechanical Engineering 1996118 74-82. (https://doi.org/10.1115/1.2795948)

96 Silver AE \& Vita JA. Shear stress-mediated arterial remodeling in atherosclerosis: too much of a good thing? Circulation 2006113 2787-2789. (https://doi.org/10.1161/ CIRCULATIONAHA.106.634378)

97 Pries AR, Reglin B \& Secomb TW. Remodeling of blood vessels: responses of diameter and wall thickness to hemodynamic and metabolic stimuli. Hypertension 200546 725-731. (https://doi. org/10.1161/01.HYP.0000184428.16429.be)

98 Chen Q, Jiang L, Li C, Hu D, Bu JW, Cai D \& Du JL. Haemodynamicsdriven developmental pruning of brain vasculature in zebrafish. PLoS Biology 201210 e1001374. (https://doi.org/10.1371/journal. pbio.1001374) 
99 Price RJ, Less JR, Gieson EJ \& Skalak TC. Hemodynamic stresses and structural remodeling of anastomosing arteriolar networks: design principles of collateral arterioles. Microcirculation 20029 111-124. (https://doi.org/10.1038/sj/mn/7800127)

100 Adams RH, Wilkinson GA, Weiss C, Diella F, Gale NW, Deutsch U, Risau W \& Klein R. Roles of ephrinB ligands and EphB receptors in cardiovascular development: demarcation of arterial/venous domains, vascular morphogenesis, and sprouting angiogenesis. Genes and Development 199913 295-306. (https://doi.org/10.1101/gad.13.3.295)

101 Weijts B, Gutierrez E, Saikin SK, Ablooglu AJ, Traver D, Groisman A \& Tkachenko E. Blood flow-induced Notch activation and endothelial migration enable vascular remodeling in zebrafish embryos. Nature Communications 20189 5314. (https://doi.org/10.1038/s41467-01807732-7)

102 Othman-Hassan K, Patel K, Papoutsi M, Rodriguez-Niedenfuhr M, Christ B \& Wilting J. Arterial identity of endothelial cells is controlled by local cues. Developmental Biology 2001237 398-409. (https://doi.org/10.1006/dbio.2001.0383)

103 De la Paz NG \& D'Amore PA. Arterial versus venous endothelial cells Cell and Tissue Research 2009335 5-16. (https://doi.org/10.1007/ s00441-008-0706-5)

104 Weber KT, Sun Y, Katwa LC, Cleutjens JP \& Zhou G. Connective tissue and repair in the heart. Potential regulatory mechanisms. Annals of the New York Academy of Sciences 1995752 286-299. (https://doi.org/10.1111/j.1749-6632.1995.tb17438.x)

105 Schneider PJ \& Deck JD. Tissue and cell renewal in the natural aortic valve of rats: an autoradiographic study. Cardiovascular Research 1981 15 181-189. (https://doi.org/10.1093/cvr/15.4.181)

106 Von Knobelsdorff-Brenkenhoff F, Karunaharamoorthy A, Trauzeddel RF, Barker AJ, Blaszczyk E, Markl M \& Schultz-Menger J. Evaluation of aortic blood flow and wall shear stress in aortic stenosis and its association with left ventricular remodeling. Circulation: Cardiovascular Imaging 20169 e004038. (https://doi.org/10.1161/ CIRCIMAGING.115.004038)

$107 \mathrm{Qu} \mathrm{X}$, Violette K, Sewell-Loftin MK, Soslow J, Saint-Jean L, Hinton RB, Merryman WD \& Baldwin HS. Loss of flow responsive Tie1 results in impairedaortic valve remodeling. Developmental Biology 2019455 73-84. (https://doi.org/10.1016/j.ydbio.2019.07.011)

108 Korhonen EA, Lampinen A, Giri H, Anisimov A, Kim M, Allen B, Fang S, D'Amico G, Sipila TJ, Lohela M, et al. Tie1 controls angiopoietin function in vascular remodeling and inflammation. Journal of Clinical Investigation 2016126 3495-3510. (https://doi. org/10.1172/JCI84923)

109 La Porta S, Roth L, Singhal M, Mogler C, Spegg C, Schieb B, Qu X, Adams RH, Baldwin HS, Savant S, et al. Endothelial Tie1-mediated angiogenesis and vascular abnormalization promote tumor progression and metastasis. Journal of Clinical Investigation 2018128 834-845. (https://doi.org/10.1172/JCI94674)

110 Savu O, Jurcut R, Giuşcă S, van Mieghem T, Gussi I, Popescu BA, Ginghină C, Rademakers F, Deprest J \& Voigt JU. Morphological and functional adaptation of the maternal heart during pregnancy. Circulation: Cardiovascular Imaging 20125 289-297. (https://doi. org/10.1161/CIRCIMAGING.111.970012)

111 Hunter S \& Robson SC. Adaptation of the maternal heart in pregnancy. British Heart Journal 199268 540-543. (https://doi. org/10.1136/hrt.68.12.540)
112 Pierlot CM, Lee JM, Amini R, Sacks MS \& Wells SM. Pregnancyinduced remodeling of collagen architecture and content in the mitral valve. Annals of Biomedical Engineering 201442 2058-2071. (https://doi.org/10.1007/s10439-014-1077-6)

113 Pierlot CM, Moeller AD, Lee JM \& Wells SM. Pregnancy-induced remodeling of heart valves. American Journal of Physiology: Heart and Circulatory Physiology 2015309 H1565-H1578. (https://doi. org/10.1152/ajpheart.00816.2014)

114 Mathieu P, Bosse Y, Huggins G, Corte A, Pibarot P, Michelena H, Limongelli G, Boulanger M, Evangelista A, Bedard E, et al. The pathology and pathobiology of bicuspid aortic valve: state of the art and novel research perspectives. Journal of Pathology 20151 195-206.

115 Badylak SF. Regenerative medicine approach to heart valve replacement. Circulation 2005111 2715-2716. (https://doi. org/10.1161/CIRCULATIONAHA.105.542837)

116 Rath S, Salinas M, Villegas AG \& Ramaswamy S. Differentiation and distribution of marrow stem cells in flex-flow environments demonstrate support of the valvular phenotype. PLOS ONE 201510 e0141802. (https://doi.org/10.1371/journal.pone.0141802)

117 Kennamer A, Sierad L, Pascal R, Rierson N, Albers C, Harpa M, Cotoi O, Harceaga L, Olah P, Terezia P, et al. Bioreactor conditioning of valve scaffolds seeded internally with adult stem cells. Tissue Engineering and Regenerative Medicine 201613 507-515. (https://doi. org/10.1007/s13770-016-9114-1)

118 Castellanos G, Nasim S, Almora DM, Rath S \& Ramaswamy S. Stem cell cytoskeletal responses to pulsatile flow in heart valve tissue engineering studies. Frontiers in Cardiovascular Medicine 2018558. (https://doi.org/10.3389/fcvm.2018.00058)

119 Chester AH \& Taylor PM. Molecular and functional characteristics of heart-valve interstitial cells. Philosophical Transactions of the Royal Society of London: Series B, Biological Sciences 2007362 1437-1443. (https://doi.org/10.1098/rstb.2007.2126)

120 Wu C, Daugherty A \& Lu HS. Updates on approaches for studying atherosclerosis. Arteriosclerosis, Thrombosis, and Vascular Biology 2019 39 e108-e117. (https://doi.org/10.1161/ATVBAHA.119.312001)

121 Cote N, Mahmut A, Bosse Y, Couture C, Page S, Trahan S, Boulanger MC, Fournier D, Pibarot P \& Mathieu P. Inflammation is associated with the remodeling of calcific aortic valve disease. Inflammation 201336 573-581. (https://doi.org/10.1007/s10753-0129579-6)

122 Weiler M, Yap CH, Balachandran K, Padala M \& Yoganathan AP. Regional analysis of dynamic deformation characteristics of native aortic valve leaflets. Journal of Biomechanics 201144 1459-1465. (https://doi.org/10.1016/j.jbiomech.2011.03.017)

123 Yip CY, Chen JH, Zhao R \& Simmons CA. Calcification by valve interstitial cells is regulated by the stiffness of the extracellular matrix. Arteriosclerosis, Thrombosis, and Vascular Biology 200929 936-942. (https://doi.org/10.1161/ATVBAHA.108.182394)

124 El-Hamamsy I, Balachandran K, Yacoub MH, Stevens LM, Sarathchandra P, Taylor PM, Yoganathan AP \& Chester AH. Endothelium-dependent regulation of the mechanical properties of aortic valve cusps. Journal of the American College of Cardiology 2009 53 1448-1455. (https://doi.org/10.1016/j.jacc.2008.11.056)

125 El-Hamamsy I, Yacoub MH \& Chester AH. Neuronal regulation of aortic valve cusps. Current Vascular Pharmacology 20097 40-46. (https://doi.org/10.2174/157016109787354088)

Received in final form 7 January 2020

Accepted 17 February 2020

Accepted Manuscript published online 17 February 2020 (c) 2020 The authors Published by Bioscientifica Ltd
This work is licensed under a Creative Commons Attribution-NonCommercial-NoDerivatives 4.0 International License. ded from Bioscientifica com at $04 / 26 / 2023$ 12:48:34AM 